\title{
O conceito funcional de pessoa na bioética secular
}

\section{The funtional concept of person on secular bioethics}

*Everaldo Cescon

Resumo: Defende-se que, nos dilemas bioéticos, o fundamental é decidido no âmbito ontológico. É fundamental responder a interrogações sistemáticas tais como: o que é uma pessoa? Quem é pessoa? A estas questões correspondem respostas de duas tendências opostas: uma tendência reducionista, no contexto de uma bioética secular, devedora do primado da ação, que argumenta em favor de uma separabilidade entre pessoa, ser humano e vida humana; e outra tendência, no contexto de uma bioética metafísica, que sustenta uma intrínseca identidade entre pessoa, ser humano e vida humana. A primeira faz o ser da pessoa coincidir com o exercício de uma determinada capacidade, uma função não é uma hipostatização abstrata, mas é inseparável do sujeito ontológico que é a sua condição de possibilidade. A segunda remete ao substancialismo e ao hilemorfismo como explicações do ser humano real, permitindo justificar a presença no homem de um princípio específico ontológico de unificação das propriedades e de permanência das funções e dos atos, presente, independentemente, da sua manifestação exterior atual, e reconhecer o estatuto atual da pessoa no ser humano, inclusive, em condições de potencialidade ou de privação.

Palavras-chave: bioética, ética, pessoa, funcionalismo, substancialismo.

\begin{abstract}
To argue that in bioethical dilemmas the bottom line is decided within the ontological. It is essential to respond to systematic questions such as: what is a person? Who is the person? These issues are two opposite trends: responses of a reductionist tendency, in the context of a secular bioethics debtor of the primacy of action, which argues in favor of separability between person, human being and human life; and another trend, in the context of a metaphysics bioethics, which holds an intrinsic identity between person, human being and human life. The first does coincide the being of person with the pursuit of a given capacity, a function is not an abstract hypostatization, but is inseparable from the ontological subject that is its condition of
\end{abstract}

* Professor do PPG em Filosofia na Universidade de Caxias do Sul, Caxias do Sul, Brasil. Endereço postal: Rua Ludovico Cavinato, 680, apto. 42 - Bairro Nossa Senhora da Saúde-Caxias do Sul, RS - CEP 95032-620. <everaldocescon@hotmail.com>.

\begin{tabular}{|l|l|l|l|l|l|}
\hline Veritas & Porto Alegre & v. 58 & n. 1 & jan./abr. 2013 & p. 190-203 \\
\hline
\end{tabular}


possibility. The second reference is made to the substancialism and to the hylemorphism as explanations of the actual and real human being to justify the presence in man of the specific ontological principle of unification of this properties and permanence of functions and acts, present irrespective of their current outer manifestation, and recognize the person's current status in humans even in conditions of deprivation or potentiality.

Keywords: bioethics, ethics, person, functionalism, substancialism.

\section{O estado da questão}

A proliferação das chamadas ciências humanas - psicologia, sociologia, etnologia, economia, etc. - fez com que se abandonasse a reflexão sobre a natureza humana enquanto tal e ameaça reduzir a antropologia filosófica ${ }^{1}$ a um repertório de museu. Parece inevitável que ocorra, com o estudo do homem, aquilo que aconteceu com o estudo do cosmos, inteiramente transferido do plano das especulações abstratas àquele da pesquisa científica experimental.

Lévi-Strauss (1989, p. 275) previu que a primeira consequência seria a dissolução do conceito único de homem: "o fim último das ciências humanas não consiste em constituir o homem, mas em dissolvê-lo", analisando-o e decompondo-o nas suas diversas manifestações. Por outro lado, parece comprovada a tese de Foucault (1999, p. 414), segundo o qual o próprio conceito de homem é unicamente "uma invenção da qual a arqueologia do nosso pensamento mostra rapidamente a data recente. E, talvez, o fim próximo".

$\mathrm{Na}$ tentativa de responder quem é o homem, os bioeticistas têm de se interrogar sobre o que significa realmente pessoa. De fato, os principais argumentos usados para delimitar o lícito do ilícito no âmbito das intervenções biomédicas tecnocientificamente possíveis sobre a vida humana pressupõem uma definição do estatuto pessoal (cf. MAHOWALD, 1995). Assim, o fundamental parece ser decidido no âmbito ontológico, repercutindo em questões práticas.

$\mathrm{Na}$ verdade, nem todos os pensadores consideram necessário usar o conceito de pessoa em bioética. Também não faltam os que julgam tal conceito inoportuno. Para outros, é totalmente supérfluo, visto que

1 A antropologia, como reflexão sobre o homem - no sentido de "ser humano" (em grego anthropos) -, pode também ser entendida como estudo das diversas formas culturais, nas quais a humanidade exprime-se nos vários ambientes históricos e geográficos (antropologia cultural). Aqui, porém, o termo e o adjetivo correspondente serão sempre usados na sua acepção filosófica, que indica não uma descrição de fato, mas a investigação racional que procura descobrir aquilo pelo qual um ser humano é humano e o que lhe confira a sua subjetividade individual. 
[...] a noção de pessoa não corresponde a nada do que se coloca ou a nível substancial ou ao nível da descrição da vida individual biológica. [...] O reconhecimento de uma classe de seres como pessoas é, portanto, fruto de uma escolha e decisão ética, bem como totalmente artificial e não natural será o critério com base no qual os pertencentes a esta classe serão considerados pessoas (LECALDANO, 2002, p. 220). ${ }^{2}$

Em outras palavras, não faria sentido apelar à pessoa para justificar a escolha de tutelar certos indivíduos e não outros, dado que ela mesma seria um produto convencional de tal escolha. Não faz diferença, então, eliminar do debate este conceito, visto que ele não tem função alguma.

Outros chegam à mesma conclusão por uma via oposta. Estão convencidos de que a "noção de 'pessoa' não é uma noção moral, isto é, uma noção valorativa, mas [...] uma noção descritiva. [...] Isto deixa claro que o mero conhecimento de tal noção não serve para saber o que devemos fazer em relação à pessoa" (MORI, 1993, p. 29). ${ }^{3}$

Segundo outros, ainda, posto que a controvérsia sobre o conceito de pessoa, como acontece a todas as grandes problemáticas filosóficas, não pode ser decidida, os problemas bioéticos concretos devem ser enfrentados com argumentos que não recorrem aos princípios últimos. É nesta linha que se situa o famoso Relatório de Warnock de 1984 que, na Inglaterra, representou um ponto de referência fundamental para o debate bioético.

De opinião contrária, porém, são os estudiosos que dão ao conceito de pessoa um peso decisivo, rebatendo as objeções feitas. À primeira objeção retrucam que, se realmente os indivíduos pertencentes a uma certa classe são considerados pessoas, é preciso explicar porque justamente eles, e não outros, merecem esta consideração. Há algo na realidade concreta deles que justifica esta escolha ética. Nesta lógica, foi observado que pessoa é, em primeiro lugar, um conceito descritivo e que o atribuindo a alguém nos limitamos a constatar que um indivíduo apresenta as propriedades que competem a uma pessoa. É num momento lógico sucessivo que a noção em questão assume uma validade normativa enquanto algumas das propriedades descritivas atribuídas às pessoas são consideradas relevantes para o tratamento moral de quem as possui.

2 " [...] la nozione di persona non corrisponde a nulla che si colloca o a livello sostanziale o a quello della descrizione della vita individuale biologica (...) Il riconoscimento di una classe di esseri come persone è dunque frutto di una scelta e decisione etica, così come del tutto artificiale e non naturale sarà il criterio in base al quale gli appartenenti a questa classe saranno considerati persone" (Tradução do autor).

3 “la nozione di 'persona' non è affatto una nozione morale, cioè una nozione valutativa, ma [...] una nozione descrittiva. [...] Questo chiarisce che la mera conoscenza di tale nozione non serve per sapere che cosa dobbiamo fare nei confronti della persona" (Tradução do autor). 
Por isso, o problema da pessoa constitui um nó decisivo, do qual todas as escolhas ulteriores dependem.

Quanto à segunda e à terceira objeções, deixa-se a palavra a um representante da bioética secular, ${ }^{4}$ Hugo Tristam Engelhardt:

A medicina lida com pessoas. [...] Portanto, é crucial reconhecer quando a vida das pessoas começa e quando termina, de maneira a saber em relação a quem a medicina, e a assistência à saúde em geral, tem suas obrigações. Os médicos, enfermeiros e demais profissionais da área de saúde precisam saber quando estão diante de uma pessoa (1991, p. 342).

Portanto, estamos diante de uma questão decisiva para saber o que devemos fazer. Não é, porém, somente uma exigência de ordem prática. $O$ ser humano é obrigado pelo seu próprio progresso a repensar a si mesmo. Neste sentido, o verdadeiro problema diante do qual a biomedicina situanos é o problema da nossa identidade. Torna-se fundamental responder a algumas interrogações sistemáticas tais como: o que é uma pessoa? Quem é pessoa? Como devemos tratar a pessoa? A estas questões correspondem outras tantas respostas diversificadas.

No intuito de apontar respostas, indica-se, primeiramente, que o principal equívoco está na diversidade das concepções filosóficas de pessoa. Neste aspecto, é possível identificar duas tendências opostas:

4 O princípio cardeal da bioética secular é tradicionalmente expresso com a fórmula etsi Deus non daretur, significando que "leigo" é aquele que pensa como se Deus não existisse. Esta abordagem garante idêntico respeito e idêntica consideração ética a cada pessoa, prescindindo das suas convicções religiosas. Numa sociedade "laica", a confissão religiosa assumida pela maioria dos indivíduos não é transformada numa imposição para quem não se reconhece naquelas convicções. Trata-se, portanto, de um requisito essencial para a manutenção das liberdades individuais e da convivência pacífica numa sociedade cada vez mais caracterizada pelo pluralismo ético e religioso. A bioética secular é, atualmente, um conjunto de diferentes visões. Entretanto, é possível identificar alguns denominadores comuns a partir dos quais definir a abordagem secular à bioética e distingui-la das abordagens religiosamente inspiradas: a) a centralidade, nas decisões acerca da vida e da morte, da autonomia e da liberdade individual, de acordo com as diferentes acepções que tais conceitos podem assumir; b) o valor atribuído à qualidade da vida, mesmo que diversamente entendida segundo os diferentes critérios de avaliação; c) a disponibilidade da vida, em relação às diferentes e pessoais concepções de valor; d) a ética entendida como disciplina essencialmente humana, isto é, fruto da reflexão racional dos homens e não como um conjunto de princípios "dado" de uma vez por todas por alguma autoridade moral ou inscrito na natureza. Entendida neste sentido, a bioética secular distingue-se, por exemplo, da bioética católica, que descende do Magistério da Igreja Católica Romana e afunda as suas raízes em princípios tais como a indisponibilidade da vida humana, concebida como dom de Deus e derivada da noção de criaturalidade, a ideia de "natureza" como critério normativo para a reflexão ética, que deve ser conforme o desígnio inteligente com o qual Deus projetou o mundo e os seus eventos "naturais", a inviolabilidade da vida humana como princípio prioritário em relação à consideração da sua qualidade. 
uma tendência reducionista (e, às vezes, estensionista), no contexto de uma bioética chamada secular, que argumenta em favor de uma separabilidade (de princípio) e de uma separação (de fato) entre pessoa, ser humano e vida humana, reduzindo, portanto, o âmbito de aplicação do conceito de pessoa em relação aos seres humanos e, às vezes, estendendo-o a seres não humanos; e outra tendência, no contexto de uma bioética metafísica, que sustenta uma intrínseca identidade (de princípio e de fato) entre pessoa, ser humano e vida humana.

A primeira tendência, diversificada internamente, introduz uma verdadeira virada no senso comum, o qual nos sugere, intuitivamente, a equiestensionalidade dos termos "pessoa" e "ser humano". A segunda tendência é unitária na sua proposta teórica e prática e está em continuidade com a tradição especulativa ocidental.

No âmbito deste texto, entretanto, analisar-se-á tão-só a tendência separacionista tomando por referência aquele que é, muito provavelmente, o seu maior expoente: Hugo Tristam Engelhardt. ${ }^{5}$

\section{A tendência separacionista e estensionista: pessoa intermitente}

Para os que se enquadram nesta perspectiva, o ser genética e biologicamente humano não é pessoa desde o momento da fecundação, mas se torna tal em algum momento sucessivo. Consequentemente, há seres humanos que não são pessoas ou, mais precisamente, que ainda não o são. Inversamente, com relação ao fim da vida humana, esta perspectiva antecipa o fim da pessoa em relação à morte biológica natural do ser humano. Por conseguinte, há alguns seres humanos que não são mais pessoas. Em outras palavras, há uma tendência a considerar que a pessoa inicia após o início do ser humano e pode extinguir-se antes do fim da vida humana.

Pode-se afirmar que se tratam de teorias funcionalistas atualistas, isto é, que fazem o ser da pessoa coincidir com o exercício de uma determinada capacidade. Significa dizer que, para tais teorias, uma função não é uma hipostatização abstrata, mas é inseparável do sujeito ontológico que é a sua condição de possibilidade.

5 É um filósofo norte-americano, doutor em filosofia e em medicina. Entre suas principais publicações figuram: Global Bioethics, Salem, MA: M \& M Scrivener Press, 2006; The foundations of bioethics, Oxford: Oxford University Press, 1996; The foundations of Christian bioethics, Lisse: Swets \& Zeitlinger Publishers, 2000; Allocating Scarce Medical Ressource: Roman Caholic Perspectives, Washington: Georgetown University Press, 2002; Innovation and the Pharmaceutical Industry, Salem, MA: M \& M Scrivener Press, 2008. 
No homem, deve-se distinguir o nível da vida biológica, o nível da vida mental e o nível da vida da pessoa. Engelhardt afirma:

[...] o início da vida biológica humana não é o início da vida de uma pessoa como agente moral. Em ontogenia humana vivem-se meses de vida biológica antes que haja suficiente prova da vida da mente - anos se passam antes que existam provas da vida de uma pessoa como agente moral (1998, p. 308).

Para que haja uma pessoa humana deve haver vida mental de nível superior, mas não uma vida mental qualquer:

Não se pode afirmar que os fetos sejam pessoas, no sentido estrito de serem agentes morais. $\mathrm{Na}$ verdade, não existe sequer evidências para afirmar que os bebês sejam pessoas no sentido estrito. Seja qual for o tipo de vida mental que existe para os fetos e os bebês, não é a mesma dos agentes morais autoconscientes, de maneira que a condição moral dos mamíferos adultos, ceteris paribus, seria mais elevada que a dos fetos ou bebês humanos (ENGELHARDT, 1998, p. 308).

Com estas afirmações, Engelhardt torna problemático o status moral de zigotos, embriões, fetos e até mesmo dos bebês. Além disso, demonstra compartilhar das teses de Singer (2004) acerca do valor mais elevado dos animais superiores em relação aos seres humanos na fase inicial.

Segundo Engelhardt, pessoa humana é somente aquela que tem uma vida mental desenvolvida e somente por este motivo é um agente moral. Contrariamente, os seres que só têm a vida biológica humana não têm valor próprio algum. Isso significa, por exemplo, que o valor de um feto não depende do próprio feto, mas daqueles que lhe estão próximos. São as pessoas às quais o feto pertence que determinam o seu valor. Assim:

Os fetos de uma mulher que deseja uma criança adquirem considerável significado. [...] Os fetos podem ser considerados como uma forma especial de uma propriedade muito querida. [...] O oposto também ocorre. Devido às circunstâncias da concepção, das prováveis circunstâncias do nascimento, ou devido ao feto ser defeituoso ou deformado, um valor negativo pode lhe ser dado. Esses fetos podem ser considerados por muitas pessoas ameaçadores ou prejudiciais (ENGELHARDT, 1998, p. 310-311).

Também na maternidade substituta, na qual outras pessoas entram em relação com o embrião, os direitos não são direitos do embrião ou do feto, mas daqueles que estipularam o contrato. São aqueles que fizeram ou procriaram o zigoto, o embrião ou o feto a ter o direito de determinar o valor de modo definitivo. Os embriões e os fetos são propriedade privada. 
É fácil ver como, nesta perspectiva, o princípio de autonomia age de modo decisivo e solitário. Também no caso do aborto, não existe o mínimo conflito moral, visto que nos encontramos diante de uma pessoa com direitos (a mulher) e de um ser que só tem vida biológica. Não há comparação entre estas duas realidades tão diferentes.

Ao lado do princípio de autonomia atua também a negação do significado do conceito de natureza humana. Pode-se afirmar que um bebê não é merecedor de tutela enquanto não for pessoa; depende do não reconhecimento de uma dignidade intrínseca ao ser humano.

A posição de Engelhardt coincide com a de todos os que consideram que a natureza do homem é irrelevante para a moral e para o direito: em outros termos, os valores, os princípios e as regras de comportamento devem ser decididos prescindindo da natureza: "[...] não pode apelar para os desígnios do Criador. [...] as descobertas estatísticas são, no máximo, sugestivas, mas certamente não definem o que deveria ser considerado" (ENGELHARDT, 1998, p. 252). Nesta perspectiva, a natureza só tem uma importância materialista e mecanicista. É um conjunto de corpos com extensão, cujo movimento é regulado pelo acaso ou pela lei de causa e efeito. Concebida assim, a natureza não tem nada a dizer ao homem. Ela não tem um fim nem um significado e, por isso, não pode dar indicações e normas para o comportamento humano: "a natureza e suas leis não são por si mesmas moralmente normativas" (ENGELHARDT, 1998, p. 85).

Os preceitos morais devem ser postos pelo homem, porque é o homem que confere sentido e ordem à realidade. A moral tem um fundamento subjetivista, que remete à escolha exclusiva do sujeito. $O$ direito tornase unicamente a tradução formal e positiva da vontade arbitrária de um indivíduo ou de um grupo, ou ainda o puro e simples reconhecimento da autonomia individual. Logo, compreende-se porque as sociedades estão deixando à autorregulamentação quase todos os âmbitos da vida.

A negação do valor normativo da natureza e a assunção do princípio de autonomia individual acabam por atribuir à vida do homem um valor relativo, subordinado ao arbítrio do homem: é o homem que faz, que programa a realidade e a sua própria vida.

A assunção unicamente do ponto de vista biológico na consideração da vida humana guia toda a reflexão e permite escolher o que se considera mais útil. A sociedade pode decidir favorecer algumas gravidezes e não outras. Melhor, pode-se decidir também favorecer algumas espécies de animais ao invés de seres humanos. Neste sentido, seria razoável investir dinheiro em reservas naturais ao invés de fazê-lo num programa para reduzir os abortos espontâneos num país com aumento incontrolado da população. De fato, entre duas doenças, uma que causa um aumento da taxa de abortos espontâneos entre os seres humanos daquele país 
e a outra numa espécie de mamíferos não humanos em via de extinção, pode-se corretamente considerar que o investimento na pesquisa para salvar os mamíferos não humanos tem prioridade.

A autoridade do Estado, nesta matéria, é muito limitada, visto que o feto é propriedade privada. Portanto, não é permitido o uso da força legal para determinar as escolhas das mulheres em relação ao aborto e às técnicas de fecundação artificial. Engelhardt enfatiza a ideia de que tudo o que se refere aos estados iniciais da vida está na esfera exclusiva da autonomia pessoal:

Além do próprio corpo, os espermatozoides, o óvulo, os zigotos e os fetos que uma pessoa produz são, em termos morais seculares, primordialmente sua propriedade. São extensões e fruto do seu próprio corpo. São seus para deles dispor, até que tomem posse de si mesmos como entidades conscientes (1998, p. 311).

Este direito exclusivo é muito penetrante e chega ao ponto de os pais poderem decidir que não querem sequer ser pais no sentido limitado de ter gerado um bebê para a adoção. O termo "direito dos pais", neste caso, destaca a falta de autoridade dos outros para impor a própria vontade nas escolhas privadas.

\section{A pessoa como tal e real}

A abertura de novas fronteiras na biologia, os progressos da medicina, a nova concepção de saúde, não mais entendida como mera ausência de doenças, mas - segundo a definição dada, em 1946, pela Organização Mundial da Saúde - como pleno bem-estar físico, psíquico e social, determinaram uma série de situações novas, oportunidades e riscos, a pouco tempo, imprevisíveis. Tornou-se evidente que as ciências naturais e os poderes da técnica não são suficientes para justificar as escolhas que cada um é chamado a fazer, cada vez com maior frequência, para si mesmo e para os outros. Tais poderes servem para ilustrar aquilo que é possível, mas não aquilo que é justo fazer. É possível transplantar o fígado de um porco no corpo de um ser humano. É possível misturar os genes de duas espécies diferentes para obter cruzamentos sem precedentes na natureza. É possível desenvolver um embrião a partir do óvulo fecundado de uma mulher no útero de outra mulher. É possível clonar seres vivos, inclusive o homem. Mas será justo fazê-lo?

Por outro lado, a progressiva renúncia da filosofia a ocupar-se com o problema antropológico, reduziu-a sempre mais a um trabalho de análise linguística. 
Para cada uma das questões levantadas pela bioética, há razões seja para uma resposta afirmativa, seja para uma negativa. Mas, seja para uma, seja para outra, tais razões não podem vir dos dados científicos que, no máximo, fazem surgir a pergunta. Somente uma visão global do ser humano - para a qual não estão equipadas nem as ciências naturais nem as humanas - pode, de fato, fornecer estas razões e justificar as escolhas práticas às quais somos obrigados. Assim, voltamos à filosofia, a única capaz de ir além dos aspectos particulares e de tomar em consideração o homem enquanto tal.

Da sua parte, a própria filosofia teve de redescobrir a sua vocação original que não é de brincar com as palavras, mas de olhar para a realidade. Raramente, na história da cultura ocidental, aparecera com tanta clareza que a reflexão filosófica não nasce de uma fuga dos problemas do cotidiano, para agarrar as nuvens, segundo a irônica representação que Aristófanes (1999) fez de Sócrates numa comédia, mas da urgência de questões que, neste caso, são de vida ou de morte.

A exigência de encontrar critérios válidos, no campo bioético, não se refere somente aos indivíduos, mas a toda a humanidade, pois, neste caso, há escolhas que devem ser tomadas em nível nacional, ou regional, ou pelo menos no âmbito de uma instituição sanitária. Isto exclui seja o dogmatismo unilateral, seja toda forma de subjetivismo e relativismo. O específico da esfera pública, em contraposição à privada, é a presença simultânea de inumeráveis perspectivas que, justamente por serem diferentes entre si, fazem emergir um sólido terreno comum - o da realidade - sobre o qual se confrontar. Logo, ninguém pode ter a própria verdade (e isto exclui o relativismo), porque, como escreveu Hannah Arendt, "onde as coisas podem ser vistas por muitos numa variedade de aspectos sem que a sua identidade seja mudada [...] os que são reunidos ao seu redor sabem ver a mesma coisa mas numa diversidade total" (ARENDT, 2004, p. 43).

Neste caso, é o homem enquanto tal que deve ser recuperado na sua realidade, mesmo por meio das diversas interpretações. No editorial da revista Civiltà Cattolica de 1992, afirma-se que, seja Singer, seja Engelhardt:

[...] se limitam a observar que alguns seres possuem a autoconsciência e a racionalidade e outros não a possuem, sem se interrogarem por que existam tais atos de autoconsciência e de racionalidade e por que alguns seres humanos sejam autoconscientes e racionais enquanto outros não o são. Em outras palavras, limitam-se a constatar a existência de certos atos, mas não analisam a sua origem, por causa 
do seu empirismo e fenomenismo cético, que não lhes permite ir além da pura experiência e do puro fenômeno. ${ }^{6}$

O conceito de pessoa, originariamente elaborado pela filosofia para caracterizar o ser humano, hoje, é usado contra o próprio homem. Devido a um uso ambíguo do conceito de pessoa em bioética, vislumbra-se a possibilidade de novas discriminações pelo grau de desenvolvimento físico, psíquico e social do ser humano. Depois do escravagismo, do colonialismo, do racismo e do machismo, teremos de lutar contra a discriminação contra os zigotos, os embriões, os fetos, os bebês, as crianças, os portadores de necessidades especiais, os anciãos, os comatosos, os doentes incuráveis?

O tema da pessoa, predileto das filosofias de inspiração cristã e metafísica, é cada vez mais usado no contexto de orientação filosófica empirista-funcionalista. Contrariamente, a noção de pessoa em bioética começa a ser olhada com suspeita por quem, originariamente, formulou-a. Autores que se declaram promotores do respeito e da tutela da vida humana da concepção ao último instante preferem omitir ou ignorar a referência à pessoa por medo de cair em equívocos perigosos.

Assim sendo, emerge a interrogação: ainda tem sentido usar a categoria pessoa em bioética? Não se pode esquecer que a noção de pessoa foi teorizada pela filosofia ocidental justamente com a finalidade de caracterizar o ser humano e de justificar a sua centralidade axiológiconormativa. Trata-se de um conceito que faz parte da tradição cultural ocidental.

Para combater a ambiguidade, é indispensável que o esforço especulativo seja orientado à retematização do conceito no contexto de uma filosofia da pessoa e do humano que saiba dar razões da identidade e da coincidência entre ser humano e pessoa, fazendo eco a Paul Ricoeur com seu Meurt le personalisme, revient la personne (1983). ${ }^{7}$

Inicialmente, deve-se relembrar que a definição de pessoa foi originariamente elaborada para caracterizar o ser humano real. Isto permite introduzir um destaque de ordem epistemológica: a elaboração de um conceito não pode abdicar da realidade à qual se refere. É o conceito a ser medido pela realidade; não a realidade que se adequa ao conceito. O ponto de partida da definição filosófica sempre será a realidade, mas examinada de um certo ponto de vista, não do ponto de vista da sondagem empírica, mas do ponto de vista filosófico.

6 Tradução nossa do original italiano.

7 Publicado, originalmente, em: RICOEUR, P. Lectures 2. La contrée des philosophes. Paris: Seuil, 1992. Trad. italiana em: RICOEUR, P. La persona. Trad. de Ilario Bertoletti. 4.ed. Brescia: Morcelliana, 2006. 
A definição filosófica pretende investigar o sentido, a especificidade essencial do ser humano real, qual condição ontológica radical (cf. POSSENTI, 2006). A definição filosófica que melhor permite tematizar o conceito de pessoa em sentido global e integral, identificando-o empiricamente com o ser humano real é a definição tradicional, originariamente formulada por Boécio ${ }^{8}$ (rationalis naturae individua substantia $)^{9}$ e reformulada de modo mais completo por Tomás de Aquino (individuo subsistens in rationalis natura), ${ }^{10}$ ou seja, a pessoa é a substância (subsistente) individual de natureza racional.

Um primeiro momento da definição que deve ser esclarecido é a recuperação do conceito de substância. Seguindo Aristóteles, por substância, entende-se, em geral, determinada individualidade de alguma coisa; a substância individual é o sujeito distinto que subsiste em si, ou seja, aquilo que pertence somente a si. ${ }^{11}$ A existência da substância individual mostra-se evidenciando a contradição na qual cai quem a nega. Quem afirma que certas qualidades e certas determinações são "de" alguma coisa ou "de" alguém indica implicitamente uma substância determinada. A experiência atesta que múltiplas características referemse a um mesmo ente e mostra que os corpos mudam e transformam-se permanecendo os mesmos.

Aplicando o conceito de substância individual, assim entendida, em especial ao homem, resulta que as funções que exercita e os atos que realiza não existem em si, mas existem somente como funções e atividades "de" um indivíduo humano substancial, que é o seu referente unitário e permanente, a condição ontológica real. É a substância, assim entendida, que permite explicar a unidade (no espaço) e a permanência (no tempo) da identidade do ser humano.

8 Na literatura anglo-saxônica, assiste-se a uma recuperação da centralidade ontológica da pessoa humana em bioética: DORAN, K. What is a person? The concept and the implications for ethics. Lewiston (N. Y.): The Edwin Mellen Press, 1989; ID. "Person: a key concept for ethics", Linacre Quarterly, vol. 56, n. 4 (1989), p. 38-49; COCKBURN, D. Other human beings. New York: St. Martin's Press, 1990. Na literatura alemã, veja-se: SCHMIDINGER, H. Der mensh ist person. Innsbruck; Wien: Tyrolia Verlag, 1994. Na literatura italiana, veja-se: TETTAMANZI, D. Bioetica: nuove sfide per l'uomo. Casale Monferrato: Piemme, 1990.

9 BOEZIO, S. Contra Eutychen et Nestorium, III, 1-6; De duabus naturis et una persona Christi, III, in: MIGNE, PL col. 1345.

10 AQUINO, Tomás de. Summa Theologiae, I, q. 29, a. 3: "persona [...] significat id quod est perfectissimum in otta natura, scilicet subsistens dicitur personae"; q. 29, a. 3, ad 2: "omne individuum rationalis naturae dicitur personae"; q. 29, a. 1: "in praedicta definizione personae ponitur substantia rationalis naturae, inquantum signficat singulare in genere substantiae; additur autem rationalis naturae, inquantum significat singolare in rationalibus substantiis".

11 ARISTÓTELES. Metaphisica Z, 7, 1032b 1-6. Para uma análise do conceito de substância em Aristóteles e das críticas sobre o tema, veja-se: BERTI, E. "Il concetto di "sostanza prima" nel libro Z della Metafisica", Rivista di Filosofia, 80(1), 1989, p. 3-23. 
A definição de pessoa caracteriza ulteriormente o ser humano em referência à natureza racional. Com a expressão "natureza" indica-se, aristotelicamente, aquilo que a pessoa é em virtude do seu nascimento (ou em virtude de ter sido concebida), portanto, pelo mero fato de existir, de viver e de pertencer à espécie humana. O adjetivo "racional" não indica somente a inteligência e a racionalidade (qual capacidade cognitiva de compreensão ou capacidade lógica e instrumental de cálculo), mas aponta em sentido lato a razão, o pensamento, a palavra, a linguagem, a comunicação, a relação, a liberdade, a interioridade e a intencionalidade voltada ao todo.

A referência ao substancialismo e ao hilemorfismo como explicações do ser humano real possibilita justificar a presença no homem de um princípio específico ontológico de unificação das propriedades e de permanência das funções e dos atos, presente, independentemente, da sua manifestação exterior atual.

Justamente com base na teoria substancialista e hilemórfica, podese afirmar que o ser humano não "se torna" pessoa em razão do exercício efetivo de certas funções (tais como a relacionalidade, a sensitividade, a racionalidade, a volitividade), mas "é" pessoa em virtude da sua natureza racional. $O$ ser pessoa pertence à ordem ontológica: a posse de um estatuto substancial pessoal não pode ser adquirido ou diminuído gradualmente, mas é uma condição radical (não se é mais ou menos pessoa, mas ou se é pessoa ou não se é pessoa). A ausência, entendida como não atuação ou privação, das propriedades ou funções não nega a existência do referente ontológico, o qual permanece tal por natureza, enquanto preexiste às suas qualidades.

A presença de um princípio substancial permite reconhecer o estatuto atual da pessoa no ser humano, inclusive, em condições de potencialidade ou de privação, ou seja, de não atuação momentânea ou permanente de certas funções, devido à incompletude do desenvolvimento (no caso do embrião) ou à presença de fatores, externos ou internos, que impedem a sua manifestação.

Disso decorre que o zigoto, o embrião, o feto (bem como o neonato, ou o bebê) "já" são pessoas, visto que, mesmo não estando manifestadas em ato ao máximo grau todas as propriedades, estão presentes as condições que constituem o suporte necessário do processo dinâmico ininterrupto que permitirá a atuação de tais caracteres (especularmente, ainda são pessoas o moribundo, o ancião, o demente, o comatoso, visto que, mesmo que os sujeitos estejam privados de certas propriedades, permanece a possibilidade intrínseca à natureza). 


\section{Considerações finais}

Ao final, é inevitável perguntar se não se está assistindo a um verdadeiro eclipse da pessoa. Vê-se o conceito de pessoa sofrer uma metamorfose radical. Além das posições que defendem a sua irrelevância, mesmo as que o valorizam acabam despotenciando-o e esvaziando-o, em suma, separando-o do conceito de ser humano. Esta separação leva, inexoravelmente, ao menosprezo de ambos os conceitos. De um lado, a pessoa torna-se uma forma vazia, sem uma identidade concreta, ou identificada com um conjunto de atos mentais, fruto de pulsões e desejos que são comuns também aos animais não humanos, ou ainda reduzida ao complexo das reações, ativas ou passivas, do indivíduo, privando-a de toda consistência e subsistência própria. De qualquer forma, agir e ter passam a ser condições determinantes do ser. É-se pessoas pelas atividades que se desenvolve, por certas propriedades que se possui, não por aquilo que se é.

De outro lado, também o ser humano fica desvalorizado, seja porque incluído numa noção ampliada e mais vaga de pessoa, que o esmaga sob o plano dos animais não humanos e que se torna, por isso mesmo, mais fraco, seja porque esta mesma noção só é-lhe aplicada se e quando exercita, atualmente, as próprias faculdades mentais ou tem um certo tipo de relações com os outros e, portanto, de modo provisório, intermitente.

Verdadeiramente, como afirma Haraway (1995, p. 55), "está em jogo o fim do homem em sentido 'ocidental'", começando pelo individualismo de Engelhardt, que reflete a experiência de uma sociedade onde as ligações que originariamente unem as pessoas são substituídas pelas meramente contratuais e pela ênfase posta no direito de propriedade. O caráter pessoal reduz-se a uma vida psíquica de registro das pulsões instintivas. Disso depreende-se porque o conceito de desejo substitui sistematicamente o de vontade e a razão exclusivamente instrumental - que não só os animais não humanos, mas também as inteligências artificiais possuem - toma o lugar da inteligência.

Um elemento característico que faz de todas estas concepções uma expressão da cultura atualmente dominante é o primado da ação. $\mathrm{Na}$ civilização ocidental, a identidade dos seres reduz-se ao seu fazer e o valor, à sua funcionalidade. A pergunta "quem é?" coincide exatamente com a pergunta "o que faz?". O mito neocapitalista do homem-que-sefaz-por-si-mesmo é o símbolo eloquente deste deslizamento.

$\mathrm{Na}$ mesma direção vai a redução da pessoa a um complexo de relações. A pessoa existe somente com base na consideração social e na aceitação que resulta dela. Mais uma vez é fácil reconhecer a ideia atual, segundo a qual se é alguém porque se tem muitas relações e se 
é, contrariamente, ninguém, se marginalizados e esquecidos por todos. Daí a disputa entre os internautas para ver quem tem mais amigos nas redes sociais.

À medida que faz emergir plenamente os pressupostos da nossa vida individual e social, o debate bioético abre o espaço para a recuperação da pessoa. Talvez ainda seja possível, em nome da razão e do futuro, colocar novamente em discussão os slogans do progresso ilimitado e recuperar as coordenadas da nossa identidade, para que não se torne real a obscura profecia de um mundo onde os seres humanos não são mais pessoas e as pessoas não são mais seres humanos.

\section{Referências:}

ARENDT, Hannah. A condição humana. 10. ed. Rio de Janeiro: Forense Universitária, 2004.

ARISTÓFANES. "As Nuvens". In: Sócrates. São Paulo: Nova Cultural, 1999. (Coleção Os Pensadores).

"Chi è persona? Persona e bioetica", Civiltà Cattolica, 4 (1992), p. 547-559.

ENGELHARDT H. T. Fundamentos da bioética. Trad. de José A. Ceschin. São Paulo: Loyola, 1998. p. 346-350. . "Bioetica laica e religiosa". Bioetica - Rivista interdisciplinare, 2 (1993), FOUCAULT, M. As palavras e as coisas: uma arqueologia das ciências humanas. Trad. S. T. Muchail. 8. ed. São Paulo: M. Fontes, 1999.

HARAWAY, D. J. A Cyborg Manifesto: Science, Technology, and Socialist-feminism in the Late Twentieth Century. New York: Routledge, 1991. Trad. it: Manifesto cyborg. Donne, tecnologie e biopolitiche del corpo. Trad. it. de L. Borghi. Milano: Feltrinelli, 1995.

LECALDANO, Eugenio. Un'etica senza Dio. Roma; Bari: Laterza, 2006.

LÉVI-STRAUSS, C. O pensamento selvagem. Tradução de Tânia Pellegrini. Campinas: Papirus, 1989.

MAHOWALD, M. B. Person. In: REICH, W. T. (Org.). Encyclopedia of bioethics. IV, 2. ed. New York: MacMillan, 1995.

MORI, M. Contributo ad un chiarimento della nozione di "persona". Per un'analisi storica e concettuale della nozione "classica" e di quella "recente" di persona. In: AGAZZI, E. (Org.). Bioetica e persona. Milano: Franco Angeli, 1993.

POSSENTI, V. Il principio-persona. Roma: Armando Editore, 2006.

SINGER, Peter. Libertação animal. Porto Alegre: Lugano, 2004. 